\title{
Glyceryl trinitrate ointment in angina pectoris
}

\author{
H. H. SALEM \\ M.B., M.R.C.P.
}

S. P. Singh

M.B., F.R.C.P.

\section{Department of Cardiology, Dudley Road Hospital, Birmingham B18 7QH}

\begin{abstract}
Summary
Skin absorption of glyceryl trinitrate (GTN) has been recognized for a long time. The effect of GTN and a placebo ointment in prevention of chest pain has been assessed and compared by studying the exercise capacity in 17 patients with angina pectoris. The placebo cream was ineffective but the GTN ointment was found to have beneficial effect in relief of pain in 16 cases. This was established by the patients' capacity to exercise on a bicycle ergometer without chest pain. The beneficial effect was sustained for up to $3 \mathrm{hr}$ in 12 patients. This preparation appears to act as a long-acting nitrate and may be valuable for patients in whom $\beta$-blocking agents are ineffective or contra-indicated, and surgery is not feasible.
\end{abstract}

\section{Introduction}

Sublingual glyceryl trinitrate (GTN) and isosorbide dinitrate relieve anginal chest pain briefly (Russek, 1966; Bunn and Chremos, 1963). A longer acting preparation of nitrates would be advantageous in patients with frequent anginal symptoms, especially when $\beta$-blocking agents are contra-indicated or ineffective and surgical treatment is not feasible. Claims for such longer acting oral preparations have been made (Russek, 1966) but the results have not been convincing (Goldberg et al., 1969) and prophylactic oral nitrates are not widely used for the management of angina.

Nitrates in ointment can be used to provide absorption through the skin (Martindale, 1972); as with most cutaneous preparations, the effect should be longer lasting and sustained (Reichek et al., 1974; Karsh et al., 1978; Davidov and Mroczek, 1976). The aim of the present study was to compare the effect of a nitrate ointment with that of a placebo in patients with documented angina.

\section{Patients and methods}

Seventeen patients with typical exertional angina but not taking anti-anginal treatment were selected for the study. Eleven patients had previouslydocumented myocardial infarctions. The resting ECG showed changes consistent with ischaemic heart disease in 12 and the exercise ECG was ab-응 normal in 5. Eleven patients who had been previously 3 treated with $\beta$-blocking agents had their medication ir tailed-off at least 3 days before the study.

After a resting ECG the study was carried out in 3 o stages:

(1) Exercise with no medication.

(2) After an interval of $30-45$ min, exercise $30 \mathrm{~min}$ after application of placebo ointment over the right scapula.

(3) Exercise $30 \mathrm{~min}$ after application of GTN ointment over the left scapula and at hourly intervals $\frac{\mathbb{}}{3}$ thereafter for up to $4 \mathrm{hr}$. This was carried out of hr after stage 2 .

The patients were told that 2 different types $\vec{F}$ ointment would be used to discover which was mo co suitable for treating their symptoms. They were nơt informed that one was a placebo. However, they all invariably volunteered that the effect of one ointment (GTN) was similar to taking sublingual nitrates, either GTN or isosorbide dinitrate, which they had previously taken. This was because they experienced $\stackrel{2}{\Rightarrow}$ either some transitory throbbing sensation or actual headache.

The exercise was performed on a Godart ergometer pedalled at a constant speed of $70 \mathrm{rev} / \mathrm{min}$ against an initial work load of $500 \mathrm{kpm} / \mathrm{min} \frac{0}{3}$ increased to $800 \mathrm{kpm} / \mathrm{min}$ after $30 \mathrm{sec}$ and continued until the patient experienced typical angina. ECGs 3 were obtained immediately after the onset of pain and again 3 and $6 \mathrm{~min}$ later.

$1.8 \mathrm{~cm}$ of placebo ointment and ointment con- $\mathrm{O}$ taining $2 \%$ GTN was applied to the patient's back and spread over an area $5 \times 7.5 \mathrm{~cm}$, which was then covered with a Melolin (S \& N) dressing.

\section{Results (Tables 1 and 2)}

There were 16 men and one woman with ages $N$ ranging from 31 to 63 years (mean $50 \cdot 2$ years). All $\omega$ experienced typical angina on exercise at periods

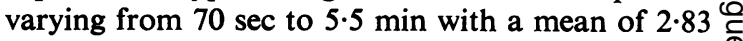
min. Placebo ointment had no significant effect on $\stackrel{\Phi}{\mathcal{Q}}$ the duration of exercise tolerance, the mean being $2.90 \mathrm{~min}$. 
TABLE 1. The effect of GTN ointment on exercise capacity in 16 patients with angina pectoris

\begin{tabular}{|c|c|c|c|c|c|c|c|c|c|c|c|c|c|}
\hline \multirow{2}{*}{\multicolumn{2}{|c|}{ Control }} & & & \multicolumn{10}{|c|}{ After GTN } \\
\hline & & \multicolumn{2}{|c|}{ Placebo } & \multicolumn{2}{|c|}{$30 \mathrm{~min}$} & \multicolumn{2}{|c|}{$1 \mathrm{hr}$} & \multicolumn{2}{|c|}{$2 \mathrm{hr}$} & \multicolumn{2}{|c|}{$3 \mathrm{hr}$} & \multicolumn{2}{|c|}{$4 \mathrm{hr}$} \\
\hline $\min$ & sec & $\min$ & sec & $\min$ & $\sec$ & $\min$ & sec & $\min$ & $\sec$ & $\min$ & $\sec$ & $\min$ & sec \\
\hline 2 & 30 & 2 & 30 & \multirow{2}{*}{\multicolumn{2}{|c|}{$\begin{array}{l}15 \\
\text { No pain } \\
15 \\
\text { No pain }\end{array}$}} & \multicolumn{2}{|c|}{ No pain } & 6 & 30 & \multicolumn{2}{|l|}{4} & \multicolumn{2}{|l|}{3} \\
\hline 2 & 30 & \multicolumn{2}{|l|}{4} & & & \multicolumn{2}{|c|}{ No pain } & \multicolumn{2}{|c|}{ No pain } & \multicolumn{2}{|c|}{ No pain } & 11 & \\
\hline 2 & & 1 & 15 & 2 & 30 & 3 & & 3 & 30 & 3 & 30 & 2 & 30 \\
\hline 4 & 30 & 3 & & 2 & 30 & 2 & 30 & 3 & & 3 & & 3 & 30 \\
\hline 2 & & 1 & 35 & 3 & & 7 & 30 & 2 & 30 & 2 & 30 & 2 & \\
\hline 3 & & 3 & & 3 & 30 & 4 & 30 & 7 & 30 & 5 & 30 & 4 & \\
\hline 2 & & 2 & 15 & 3 & 20 & 3 & 30 & 3 & & 2 & 55 & 2 & \\
\hline 4 & & 5 & & 6 & 30 & 5 & 30 & 5 & 30 & 4 & 30 & 4 & 30 \\
\hline 2 & & 1 & 20 & 3 & & 3 & & 2 & & 2 & & 2 & \\
\hline 2 & 35 & 2 & 35 & 3 & & 3 & 20 & 2 & 30 & 3 & 15 & 2 & 35 \\
\hline 1 & 40 & 2 & & 4 & & 4 & & 4 & & 3 & & 2 & \\
\hline 1 & 25 & 2 & 15 & 3 & & 4 & 30 & $\begin{array}{c}8 \\
\text { No }\end{array}$ & & 6 & 30 & 5 & 30 \\
\hline 5 & 30 & 5 & 30 & $\begin{array}{l}15 \\
\text { No }\end{array}$ & & $\begin{array}{l}15 \\
\text { No }\end{array}$ & & 12 & & 7 & & 5 & 30 \\
\hline 5 & & 4 & 30 & $\begin{array}{l}15 \\
\text { No }\end{array}$ & & $\begin{array}{l}15 \\
\text { No }\end{array}$ & & 8 & 30 & 6 & 10 & 5 & 30 \\
\hline 2 & 55 & 3 & 10 & 5 & 30 & 6 & & 4 & 30 & 4 & 15 & 4 & \\
\hline 3 & & 3 & & $\begin{array}{l}15 \\
\text { No }\end{array}$ & & No & & No & & 5 & 30 & 4 & \\
\hline 1 & 10 & 1 & 25 & 1 & 20 & 1 & 20 & 3 & 5 & 2 & 45 & 2 & 15 \\
\hline
\end{tabular}

Sixteen patients showed considerable improvement with GTN ointment and only one showed no response, despite a fall in blood pressure and tachycardia indicating adequate absorption of the ointment. The comparison with placebo in this study is the 30-min result and the findings later than this on GTN relate only to the control time and provide no comparison with placebo at one to $4 \mathrm{hr}$.

TABLE 2. Mean BP recordings $(\mathrm{mmHg})$ in various stages of testing

\begin{tabular}{ccccc}
\hline & & \multicolumn{3}{c}{ After GTN } \\
Resting & Placebo & $30 \mathrm{~min}$ & $3 \mathrm{hr}$ & $4 \mathrm{hr}$ \\
\hline $139 / 96$ & $138 / 96$ & $114 / 82$ & $116 / 81$ & $126 / 91$ \\
\hline
\end{tabular}

Thirty min after application of the ointment 5 patients experienced no pain after $15 \mathrm{~min}$ of continuous exercise, which was stopped because of exhaustion. The remaining 11 all showed considerable improvement compared with their control values. The mean duration of exercise tolerance was $6.5 \mathrm{~min}$.

At one $\mathrm{hr}$ the number of pain-free patients remained the same, and there was a further increase in the exercise tolerance of the remaining 11 , with a mean duration of $6.8 \mathrm{~min}$.

At $2 \mathrm{hr} 3$ of the 5 patients who had had no pain experienced mild discomfort but still showed marked improvement on their control times. The other 2 remained pain-free. Of the remainder, 4 continued to show improvement and one became pain-free; 4 had similar exercise times as at one $\mathrm{hr}$; and $3 \mathrm{had}$ exercise tolerance comparable with their control values.

At $3 \mathrm{hr}$ there was only one patient who was painfree. Three had pain at control times while 12 still continued to show considerable benefit from GTN. The mean duration of exercise was $5.22 \mathrm{~min}$.

At $4 \mathrm{hr}$ all patients had pain; 10 at control times and 6 still showing improvement. The mean duration of exercise was $4.03 \mathrm{~min}$ (Table 1).

Blood pressure was recorded during the resting phase, after application of placebo and after 30 min, 3 and $4 \mathrm{hr}$ after GTN cream (Table 2). The mean pulse rate at rest was a little over 78 and at 30 min after GTN cream just under $93 / \mathrm{min}$.

\section{Discussion}

The 16 patients with angina on effort who responded favourably to GTN ointment at $30 \mathrm{~min}$ showed a significant rise in pulse rate over their control values and a significant fall in blood pressure (the mean control being $139 / 96$ and at 30 minutes $114 / 82$ Table 2). This suggests that absorption of the ointment had started before this period. It would be difficult to be certain of the exact time when GTN entered the blood stream, however, because BP and pulse rate were not monitored continuously, nor were blood levels of GTN estimated. The effect appeared to last up to $3 \mathrm{hr}$ in the majority of patients, although in some there was a fair response even at $4 \mathrm{hr}$. The ECG, which had shown ischaemic changes during rest and in the control period of exercise, 
remained normal at $30 \mathrm{~min}$ and up to $3 \mathrm{hr}$ in 3 patients-this further confirmed the clinical impression that this ointment was effective.

It is surprising that, although the use of GTN ointment was first described in 1955 (Davis and Wiesel, 1955), its use has not yet gained popularity. The widespread use at one time of longer-acting oral preparations of nitrates may have prevented clinicians from trying the ointment. In recent years, $\beta$ blocking agents and surgery in selected patients have become standard prophylactic treatment for patients with angina pectoris. Beta-blocking agents may, however, be ineffective or cause unpleasant side effects, or are contra-indicated because of the presence of obstructive airways disease, cardiac failure or intermittent claudication. The authors feel that in these individuals and in patients who are unfit for surgery GTN ointment merits a trial. The main problem with this form of therapy is headaches, encountered in 3 of the patients, and individuals who get headaches with sublingual GTN tablets should not be prescribed the ointment. The ointment is readily absorbed through the skin and, if someone other than the patient is applying it, he or she should be advised to use gloves.

Oral nitrates have been used in patients with severe heart failure to reduce the work load of the ventricles, their action is relatively short and absorption may not be smooth (Williams et al., 1976).

The authors have used GTN ointment with clinical improvement, either in conjunction with or in place of oral nitrates to achieve more sustained and longer action in patients with intractable cardiac failure.

\section{Acknowledgments}

We are grateful to Dr A. Paton for his helpful criticism, Dr P. Foster for his help in the initial clinical trial and to the

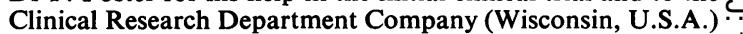
for supplying GTN and placebo cream.

\section{References}

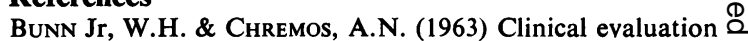
of sublingual nitrates, onset and duration of nitroglycerine and isosorbide dinitrate. Angiology, 14, 48.

Davidov, M.E. \& MroczeK, W.J. (1976) The effect of $\vec{\circ}$ nitroglycerine ointment on exercise capacity in patients $\overrightarrow{\vec{H}}$ with angina pectoris. Angiology, 27, 205.

DAVIS, T.A. \& WIESEL, B.H. (1955) The treatment of angina pectoris with a nitroglycerine ointment. American Journal of Medical Sciences, 230, 259.

GoldberG, A.N., Moran, J.F., Butterfield, T.R., G NemickAs, R. \& Bermudez, G.A. (1969) Therapy of of angina pectoris with propranolol and long-acting $\mathrm{G}$ nitrates. Circulation, 4, 847.

Karsh, D.L., UmbaCK, R.E., Cohen, L.S. \& LANGou, R.A. $\stackrel{\infty}{-}$ (1978) Prolonged action of nitroglycerine ointment on exercise tolerance in patients with angina pectoris. $\triangle$ American Heart Journal, 96, 587.

Martindale (1972) The Extra Pharmacopoeia, 26th edn, p. 752. Pharmaceutical Press, London.

ReicheK, N., Goldstein, R.E., Redwood, D.R. \& Epstein, $\frac{\mathbb{D}}{3}$ S.E. (1974) Sustained effects of nitroglycerine ointment patients with angina pectoris. Circulation, 50, 2.

RUSSEK, H.I. (1966) Therapeutic role of coronary vasodilatoos glyceryl trinitrate, i sosorbide dinitrate and pentaerythritel tetranitrate. American Journal of Medical Sciences, 252, $\overline{9}$.

Williams, D.O., Bommer, W.J., Miller, R.R., AmSterda $\bar{M}$, E.A. \& MASAR, D.T. (1976) Hemodynamic assessment of oral peripheral vasodilator therapy in chronic congenital cardiac failure: prolonged effectiveness of isosorbide dinitrate. American Journal of Cardiology, 39, 322. 